\title{
Sustainable global civilization
}

\author{
Y. Ishiguro \\ Instituto de Estudos Avançados, CTA, Brazil
}

\section{Abstract}

The fundamental cause of almost all problems facing humanity is the size of the human population, multiplied by the intense consumption. There will not be technological solutions unless the population and the consumption are reduced, because apparently the capacity of the planet has already been surpassed.

In order to enable a sustainable global civilization, some basic concepts regarding human existence need to be recognized or changed:

* The Earth is finite in space, resources and capacities of its systems;

* Man is adapted to the current equilibrium in the systems of the Earth;

* A healthy biosphere is essential for the equilibrium in the habitats for man;

* The biosphere is maintained by photosynthesis in plants;

* There is a limit to the size of the biosphere;

* An increase of human population means a reduction of those of other species;

* Perturbations in the biosphere as well as in other systems could break the equilibrium;

* In a closed system the effective fertility of each species must be that of replacement;

* There cannot be human rights that lead to the collapse of the community;

* The concept of community needs to include all humanity and the biosphere;

* Ultimately man has to live with renewable resources;

* The principles of economy need to be modified;

* The meaning of life must be found in something other than procreation or consumption;

* All ideals cannot be realized;

* Some new rationality needs to be added to the rules of community;

* The Earth can support indefinitely an abundant lifestyle in a limited global civilization;

* Human population must be reduced.

Keywords: sustainability, limits of the Earth, population, consumption, fertility control, irrational idealism, rational society, philosophical bases, capitalism. 


\section{Introduction}

In the past centuries there have been remarkable progresses in various areas such as science, technology, medicine and agriculture and today some countries enjoy the highest standards of living ever achieved in history, with high levels of education, health care, long life, comfort, leisure and material consumption. The human population grew to a level never achieved by any animal species of a comparable size. Homo sapiens is the most successful species in the history of the evolution of life.

However, various difficulties for the continuity of human community have appeared in the past decades. Individuals, organizations and governments have been trying to resolve the current and perceived future problems and continue efforts to "save the Earth". In addition to environmental problems such as global warming, species extinction, deforestation and accumulation of wastes, there are diverse social problems, too, such as poverty, avoidable diseases and famine that affect a large part of the world population. Despite the well-known prosperity in industrialized countries, miseries and sufferings in less developed countries are increasing and social polarization is intensifying in most countries. International conflicts continue to occur and a considerable fraction of every nation's economy is directed to military spending [1].

The mode of living currently practiced in industrialized societies and aspired to by others cannot be continued for long nor extended to the whole world [2]. Competitions for limited resources and space could lead to social unrests, increased international conflicts and the destruction of the systems of the Earth. Moral restraints could be thrown away and a large part of the world population could be eliminated. However, there are technologies to assure the survival of a small group of elites. Homo sapiens will not be extinct. A new civilization will emerge, perhaps wiser and more rational after the trauma, but such a transition must be avoided.

The fundamental cause of almost all problems facing humanity is the size of the human population, multiplied by the intense consumption in affluent parts of the world. Man is adapted to the current equilibrium in the systems of the planet but he has abused the very systems he depends on. China is the only country that recognizes it and has adopted concrete measures. If the current trends continue, an environmental and/or social collapse in a global scale will be inevitable in near future and the whole world will have to adopt the one-child policy mostly criticized at present, or more restrictive policies, or face the collapse of the world civilization. But the world community continues to cling to impracticable ideals and declares with a consensus that a free choice of the number and spacing of children is a human right [3]. Humanity needs to recognize the reality of the world and be more rational in selecting ideals and rules of community. There cannot be human rights that lead to the destruction of the community.

Control of human population and fertility needs to be discussed openly and the current economic and political systems that emphasize continuous expansion of consumption need to be reviewed in global long-term perspectives. The current taboo needs to be broken and the myopia corrected. 
A vibrant biosphere has been maintained for hundreds of millions of years. I believe that the Earth can support indefinitely a healthy, comfortable, abundant lifestyle that most people aspire to, if science and technology are applied wisely and if the population is controlled at a level compatible with the capacity of the Earth. But to achieve it, human mentality needs to change. A modification of human mentality will be difficult and it makes one pessimistic. But if we look at some current societies, we can be cautiously optimistic. I think that there still is time for the world community to change its ways and ensure its continuity. Man has to learn to take a global view and adapt to the inherent limitations of the planet. I propose a new ideal for humanity, that of building a sustainable rational global civilization that is in equilibrium with nature and in which all societies continue in peace, natural resources are shared by all, and a decent living is guaranteed for all who conform to the rules of community.

In order to realize a sustainable global civilization some basic concepts regarding human existence need to be recognized or changed:

- The Earth is finite in space, resources and capacities of its systems;

- Man is adapted to the current equilibrium in the systems of the Earth;

- A healthy biosphere is essential for the equilibrium in the habitats for man;

- The biosphere is maintained by photosynthesis in plants;

- There is a limit to the size of the biosphere;

- An increase of human population means a reduction of those of other species;

- Perturbations in the biosphere as well as in other systems could break the equilibrium;

- In a closed system the effective fertility of each species must be that of replacement;

- There cannot be human rights that lead to the destruction of the community;

- The concept of community needs to include all humanity and the biosphere;

- Ultimately man has to live with renewable resources;

- The principles of economy need to be modified;

- The meaning of life must be found in something other than procreation or consumption;

- All ideals cannot be realized;

- Some new rationality needs to be added to the rules of community;

- The Earth can support indefinitely an abundant lifestyle in a limited global civilization;

- Human population must be reduced.

\section{Sustainable global civilization}

The principle of evolution of life is the survival of the fittest. The evolution of human societies also followed the same principle. Many civilizations emerged, prospered and disappeared, some for natural or internal causes but many destroyed by others. Today, in a century of science, technology and globalization, international conflicts continue in various regions of the world. 
Within societies, too, there are conflicts between social classes, ethnic groups, religious sects and groups of people with specific beliefs, ideals or interests.

The industrialized nations have achieved the highest standard of living in history but it was only possible at high costs to the global ecosystem, the biosphere and the rest of the human community. These nations continue taking advantage of the labor and natural resources of less developed countries and abusing the environment and the biosphere by their intense consumption, backed by strong economic and military forces.

The basic question for humanity now is whether it follows the path of natural selection or it builds a civilization equitable to all, including future generations and the biosphere. History and the current situation point to the first path, which would necessarily lead to the elimination of a large part of the world population.

To take the second path, some fundamental changes are necessary. Societies have chosen many ideals as their guides, some of which are impracticable and wishful but most are noble in themselves. These ideals cannot all be realized in a finite world and some compromises need to be made, including adoption of some rules that are contrary to the most basic principles of humanity. Fundamentally, basic limitations of nature need to be recognized, first of all the finiteness of the planet and, secondly, the principles of the biosphere, such as the workings of food chains, the low rates of survival of progenies and the finiteness of individual life, though these principles should be adapted to human society in order to enable a sustainable rational world community.

Recent advances in science and technology, and the enormous possibilities that they demonstrate, show that man can construct a sustainable global civilization and maintain a healthy biosphere if he adopts rational rules of community and controls his population and consumption. The collective human mentality needs to evolve and the only way to do so is education, formal as well as social. A small part of the huge annual military expenditures of the world could perhaps help finance universal education, creating much better prospects for peace than the escalating buildup of weapons. Humanity collectively needs to reflect on its value system and select the most essential ideals. One of the basic requirements is a refinement and extension of the concept of community, namely, the recognition of the mutual dependence including the biosphere and the elevation of community above individuals.

\section{State of the global environment}

Many problems have been recognized in the past decades and are well known to people concerned with the present and the future of the Earth. Principal difficulties include the following types.

- Exhaustion of accumulated resources, such as fossil fuels, soils and minerals;

- Use of renewable resources above the productive capacity, such as fresh water, forest and fishery;

- Demand on the systems of the Earth above their capacities, such as processing of refuses of human life and air pollution; 
- Accumulation of man-made materials damaging to the biosphere, such as industrial wastes and toxic chemicals;

- Changes in the surface of the Earth, such as pavement, dams, deforestation and desertification;

- Perturbations of equilibrium in the global systems, such as $\mathrm{CO}_{2}, \mathrm{CFC}$, ozone and nitrogen cycle;

- Perturbations in the biosphere, such as species extinction and introduction of non-native species.

\section{Philosophical bases}

In addition to the technological progresses there have also been advances in philosophical and moral aspects that reduced abuses such as colonialism and slavery. However, humanity's philosophical bases continue mostly unchanged since the earliest civilization. Notable characteristics include unrealistic or impracticable idealism, shortsightedness, egoism, greed and brutality of individuals, social groups and nations.

It appears to me that current efforts to save the Earth suppose that technological solutions are possible without modifications of philosophical bases, rules of community, ideals and traditional customs, such as free procreation, growing population, unlimited accumulation of wealth, intense consumption of natural resources, abuse of ecosystems, interminable judicial processes, and infinite value nominally given to human life and that the effects of human activities on the biosphere, ecosystems and future generations are ignored. The current social and international rules allow a life of intense and ostensive consumption by some individuals and nations while billions of people live in misery and millions die every year of avoidable causes. Some ideals are taken to extremes by the interests of some sectors of society causing diversion of resources. Social and international conflicts are bound to occur in protest, threatening the core of social stability and the continuity of the world civilization.

The two fundamental causes are, first, the current philosophical bases, arrangements and workings of societies and, second, the finiteness of the Earth. The second factor cannot be changed in any significant ways. So the solutions must come from the first factor. There will be no technological solutions because apparently the limits of the systems of the Earth have already been surpassed.

\section{Economy and politics}

Capitalism is the only economic system that has passed the test of history, despite its well-known shortcomings, but it is one of the causes of the current situation of the world.

In most countries one of the primary policies is economic development, namely constantly increasing consumption, in order to assure employments for the growing number of people seeking means of survival. Houses, automobiles, 
appliances and all sorts of consumer items are produced in increasing quantities and their sale is promoted by all conceivable means. Increasing demands on transport and other infrastructures mean constantly expanding constructions. Growing population squeezes the job market and further expansion of economy, further consumption, is promoted. Natural resources are extracted at the highest possible rates and refuses accumulate. Wealth is concentrated in the hands of a small number of people, huge tracts of lands are fenced off, small-scale farmers are shoed off their lands and together with jobless people seek subsistence farming in small plots of land cleared from virgin forests. The biosphere shrinks, resources are exhausted, environment deteriorates, and the quality of human life sinks.

The luxurious lifestyles in the industrialized countries are broadcast to the rest of the world where most people struggle to survive from day to day. These people would naturally feel envy, resentment and anger and their frustrations are bound to explode. The series of terrorist acts are inevitable consequences. I can only try to imagine the pains of starvation or the despair and hatred of a suicide bomber. The concentration of wealth, the buildup of military power and the polarization of technological capabilities enhance the disparity between the two worlds and further intensify the cycle of protests and suppression.

Humanity has experimented with various political systems and apparently selected democracy as the best. However, in the current world, it has an essential shortcoming in that the elected representatives are practically inhibited to have long-term visions. For most politicians the future is the next election and they would attend to the immediate wishes of the people they represent. Attempts to limit consumption, economic development or human rights would be a political suicide for them.

Some modifications of political, as well as economic, systems are necessary but at present decisions are in the hands of the people and nations with interests in the status quo and environmentalists and other visionaries who advocate changes have no real power. I cannot propose any concrete alternative systems except intensive education and the adoption of more rational rules of community. I hope that education can remedy myopia and other primitive aspects of human nature so that the common people would have long-term global visions and their elective power and demands for change would lead to more rational systems.

\section{Human population and the limits of the Earth}

The human population was a few hundred million at the beginning of the Christian era and increased slowly over the next 1800 years to less than 900 million. The rate of growth accelerated since then and the population reached six billion in 1999. The world population is increasing by more than 70 million per year and is projected to reach nine billion in the middle of the century.

Ecological footprint analyses show that the capacity of the Earth is adequate to sustain a population of a billion at the current rate of consumption in the United States and two billion at the rate in European countries. 


\section{Laws of nature and rational society}

As the society guarantees a secure life for everyone, individuals need to assume their part of responsibilities and the definitions of human rights, individual freedom, crime and punishment need to be modified. In many societies ideals and interests of some individuals or sectors led to the definition as crime of some activities that are really a matter of personal choice without prejudice to others, resulting in much waste of resources that could be used for the benefit of the community. The most notable example is the current policy on narcotic drugs. Some people apparently choose to use them knowing that the consequence is much suffering and a shortened life. Liberalization of narcotic drugs would eliminate clandestine traffic and drug wars. The current prohibition is actually creating demands and violent organizations. The so-called drug war will never be won, just as the alcohol prohibition failed. As long as there is a demand, there will be supplies.

Most criminals are produced by the society, namely, many people are driven to activities defined as crime in order to survive in unjust societies that allow some individuals to live a luxurious life alongside slums and shantytowns. Once the stable equitable society is achieved there will be no need to commit crimes for survival. However, there will always be some individuals who commit acts of violence and deception. These people, a very small minority, need to be removed from the society. The concepts of human rights and justice need to be modified, with community placed above individuals. Communities and nations have, throughout history, resorted to war to guarantee their survival and peace, killing innocent people and destroying material bases of civilization. It would be much more rational to apply this principle internally in order to guarantee the continuity and peace of each community.

Abortion and euthanasia also need to be viewed more rationally. Humanity needs to recognize that life is finite, that life depends on the termination of other lives and that unlimited procreation, survival of all progenies and individual life beyond biological limits are impracticable ideals. The most fundamental ideal should be the continuity and peace of the community. In nature the rates of survival of progenies are quite small: it is the way the biosphere functions. Man alone cannot be an exception, unless he controls himself in some way. Human rights should include the freedom of individuals to choose how to live and die.

In most societies, judicial processes continue interminably in the name of human rights and justice, diverting resources that can be used for better ends. In the world where millions die of starvation and avoidable diseases annually, this is an example of irrational idealism.

Other examples of individual choice that many societies worry about or even criminalize include smoking, drinking, obesity, seat belt and motorcycle helmet.

In summary the sustainable global civilization should assure, on one hand, universal education, conditions for a decent life and freedom to choose how to live and, on the other hand, individual responsibility to ensure its continuity and equality of all who conform to rational rules of community. 


\section{Looking toward the future}

Human history is full of conflicts since the first known civilization to this day. The future appears to be the continuation of this tradition, with larger scales and higher efficiencies in the killing and destruction. There are means to destroy large cities and kill millions of people in a matter of seconds or minutes. A large part of the world population lives in precarious conditions. Social and international conflicts continue in various parts of the world and will intensify with increasing shortages of essential resources and further polarization.

Science and technology have been trying to maintain a balance between increasing demands, production capacities, dwindling resources and preservation of the environment. However, the population increased to the limit at each moment and prevented advances in the living conditions of the majority, with benefits reaching to only a third of the world population at present. The possibilities of science and technology appear limitless but the planet is finite. The equilibrium of the systems is delicate and can be broken by small perturbations. Stored resources are being exhausted, some renewable resources are being used beyond replacement levels, species are vanishing and the environment is deteriorating.

Man has behaved till now like a child who disregards its future. After a few thousand years of civilization man learned ways to use nature to his convenience and, like an adolescent euphoric of his newly found power, ignored his future and abused his own home. The human population has exceeded the carrying capacity of the planet. To ensure the continuity of the global community man has to change his ways and an essential measure is a reduction of the population and consumption. It is time for man to grow and plan for a long mature life. Figure 1 shows a summary of the current situation and the two alternative paths to the future.

The most basic principle is that in a closed system the fertility must be that of replacement. In nature this principle is maintained by the food chain and natural constraints such as available space, variations of climate and limits of photosynthesis. Man, however, has no predator. Historically other forces such as diseases and food shortages, as well as wars, limited the population but man has strived to eliminate these factors one by one, except war, and today many diseases have been practically eliminated or can be cured routinely and the food supply is abundant overall with adequate reserves for any emergencies. Advances in medicine and sanitation, as well as in other areas, have reduced infant mortality and increased the average life span in most countries. Positive results have been glorified and negative consequences and their causes have been ignored.

Human history has been formed by power plays by nations, organizations and individuals, as in wild animal societies. The end result is the current situation that will most likely lead to the collapse of the global ecosystem or another world war. Humanity needs to recognize the inherent limitations of the planet and adopt more rational rules and a sense of global community. In place of trying to accommodate the needs of an increasing population, humanity can apply the 
advances in science and technology to improve the living conditions of a limited constant population. Principles of economy also need to change, with characteristics such as: employments distributed to all in a basically constant and routine economy based on renewable resources, minimum utilization of stored resources, constructions limited mostly to maintenance, improvement and replacement. Some popular activities that involve wasteful consumption in the name of sports, leisure or economic development will have to be stopped. Life would be rather dull for some people, compared to that in current industrialized societies. But the only alternative, that I can see, is a global conflict with all its consequences.

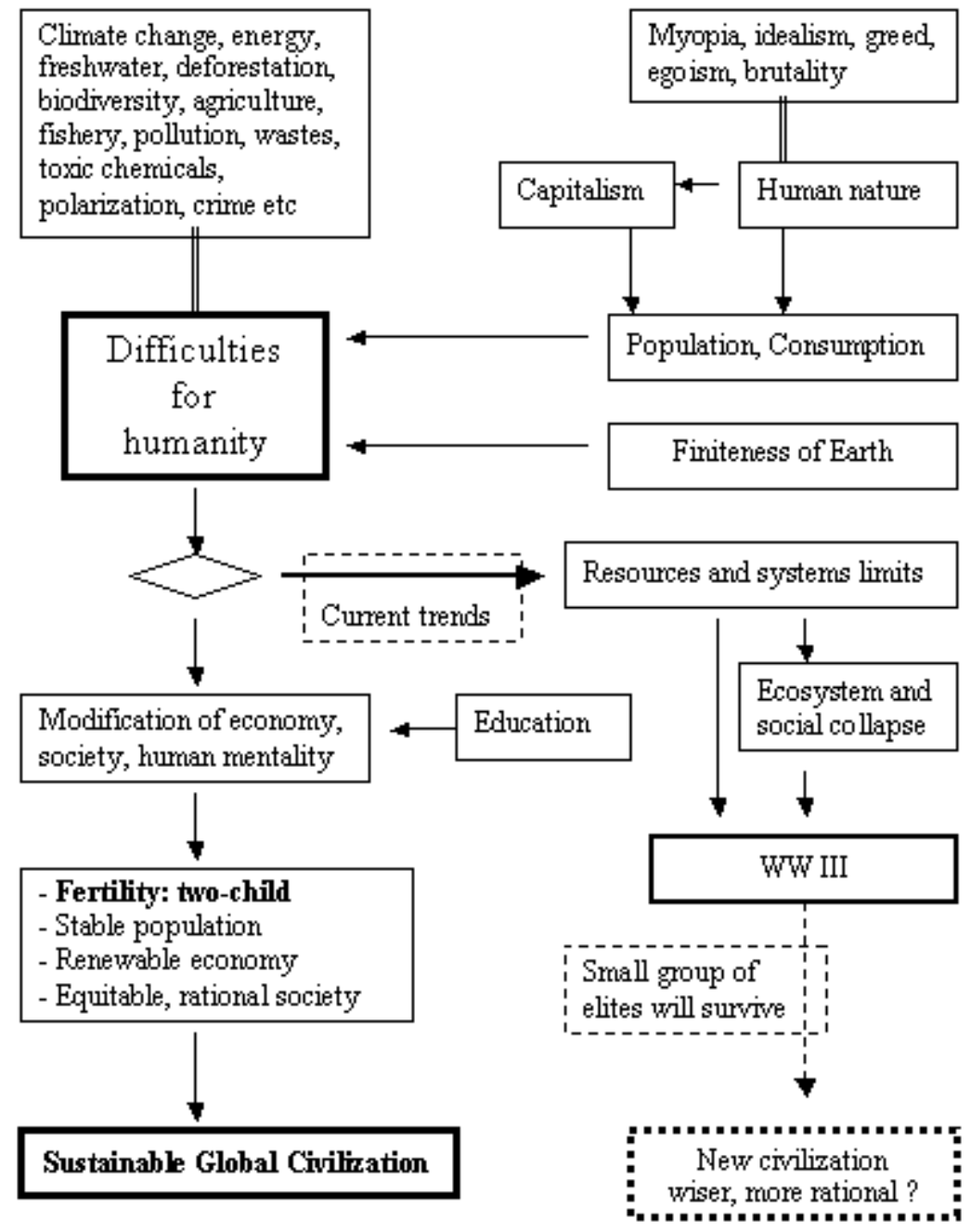

Figure 1: Summary of the current situation and the alternative paths to the future. 
The relation of man with nature needs to be based on the recognition of his dependence on the equilibrium in the intricate systems of the Earth and in the biosphere. Man's position must be found within the limitations of the Earth. It is time to abandon the posit that a territorial conquest, a growing population and an expanding economy mean an advance of human existence. Control of the population is not a solution in itself but a necessary condition and the first step.

Man is the culmination of the evolution of life on this unique and beautiful planet and his intelligence is the most remarkable phenomenon other than life itself. With his logical mind, accumulated scientific knowledge and technological abilities man can construct a sustainable rational global civilization in harmony with nature. If he so chooses, man can assure the continuity of the biosphere, his own intellectual evolution and understanding of the universe.

\section{Acknowledgments}

The author is grateful to the Instituto de Estudos Avançados of Comando-Geral de Tecnologia Aeroespacial (CTA) for the permission to write a book that forms the basis of this essay. The author applauds the visions of the directors to allow studies of a subject beyond the normal activities of the institution. The opinions and views expressed are entirely of the author and do not necessarily reflect those of the institution or any person thereof.

\section{References}

[1] Ishiguro, Y, Civilização Global Sustentável, Booklink, Rio de Janeiro, 2005.

[2] Earth Council, Ecological footprint of nations, http://www.ecouncil.ac.cr/rio/focus/report/english/footprint/.

[3] Program of action of the United Nations International Conference on Population and Development, Cairo, 1994, Section 7.3, http://www.iisd.ca/Cairo/program/p00000.html. 